\title{
O JOGO COMO CONTEÚDO DE ENSINO NA PERSPECTIVA DOS ESTUDOS DO IMAGINÁRIO SOCIAL
}

\author{
DR. JEFERSON RETONDAR \\ Professor adjunto do Instituto de Educação Física e Desportos (IEFD) da Universidade \\ do Estado do Rio de Janeiro (UERJ), Doutorado na Universidade Gama Filho (UGF) \\ Laboratório do Imaginário Social Sobre as Atividades \\ Corporais e Lúdicas (Lisacel/IEFD/UERJ) \\ (Rio de Janeiro - Rio de Janeiro - Brasil) \\ E-mail: retondar@oi.com.br
}

\section{RESUMO}

O objetivo deste artigo é refletir sobre o jogo como um dos conteúdos fundamentais de ensino da Educação Física, considerando-o a partir de seus pressupostos simbólico, mítico e estético. A partir do recorte interpretativo dos estudos de imaginário social, compreendemos que para além dos inúmeros sentidos que motivam os jogadores a jogarem, há também, durante o processo do ato de jogar, a emergência de alguns sentidos originários que reatualizam o jogo e o jogar como uma experiência significativa e, ao mesmo tempo, misteriosa.

PALAVRAS-CHAVES: Jogo; imaginário social; símbolo; mito; estética. 


\section{INTRODUÇÃO}

Os indivíduos participam de diferentes maneiras, de seu universo cultural e social, através dos meios de comunicação de massa, da internet, da família, do esporte, dos amigos no cotidiano, do universo religioso e também por meio do ensino formal da Educação Física nas escolas, pois aprendem sobre valores, crenças, desejos, limites e possibilidades de ser e de agir. Especialmente durante essas aulas, os alunos entram em contato com o movimento expressivo manifestado, dentre outras formas, pelo jogo.

Os alunos não chegam zerados à escola. Antes, são portadores de uma história de vida, de desejos, de crenças e de sonhos que se manifestam por suas representações, pelo discurso oral e pelo discurso não-verbal. São as representações que fixam simbolicamente os indivíduos no mundo. É por meio delas que podemos identificar os sentidos profundos que dão sustentação ao presente vivido e apontam para o futuro próximo. Portanto, não é possível pensar em uma intervenção pedagógica em Educação Física desconsiderando os estudos e as pesquisas no campo interdisciplinar do Imaginário Social.

As representações, que se vinculam com os valores, se consolidam em éticas ou estéticas, guiam as ações, suscitam conflitos que podem aumentar, diminuir ou mesmo desaparecer da mesma maneira que apareceram.

A representação enquanto mediação dos mundos, subjetivo e objetivo se constroem entre a cultura e a ideologia, entre o sensível e o inteligível, formando uma unida viva de sentidos que se encontram em constante movimento suscetível de novas formações, de novos sentidos em face de elementos imprevisíveis dos quais todos nós estamos suscetíveis.

A representação social é fruto da condensação de alguns sentidos da cultura e da ideologia na qual o sujeito se encontra inserido, mas que aponta na direção da transcendência daquilo que é estritamente cultural e daquilo que é estritamente ideológico, pois também se enreda no ancestral e aponta para os sonhos e para os desejos. A representação não se limita a uma explicação na sua totalidade nem como manifestação previsível descrita pela cultura, nem como reflexo da ideologia. A representação é um amálgama de sentidos impulsionado pela dimensão afetivo-simbólica.

A linguagem cumpre o papel de mediadora entre nós e o mundo. Para além da linguagem verbal, o movimento corporal se apresenta também como uma fecunda possibilidade de comunicação e de expressão. Assim, torna-se necessário o professor estar cada vez mais apto a decodificar a linguagem silenciosa dos movimentos corporais de seus alunos em vias de estabelecer com eles uma comunicação mais profunda, e, ao mesmo tempo, mais eficaz no que tange à intervenção profissional, considerando as formações integrais do educando e as representações que balizam a maneira como agem no interior do processo pedagógico. 
○ jogo é um elogio à gratuidade, pois não busca outra coisa se não a autossatisfação. É fim em si mesmo. Trata-se de uma atividade que é destituída de qualquer julgamento moral; relaciona-se diretamente com a dimensão imprevisível, com o acaso, como um dado da realidade que lhe é inerente, produzindo níveis diferenciados de excitação advindos da tensão e da incerteza peculiares à proposta de cada jogo. Sua busca é sempre por um "objeto" imaterial como: a superação, a autossuperação, a felicidade, a alegria, o entusiasmo, o reconhecimento e o prazer. Portanto, busca sentidos que sempre estão muito além das palavras e da significação racional.

A realidade do jogo ao acionar, por exemplo, sentidos como a superação e a autossuperação dentro da escola, podem se enraizar na história de vida dos alunos com inúmeras repercussões morais, estéticas e sociais. Ao ser apropriado como espaço de alegria e de celebração da gratuidade, o jogo, remete àquele que joga à vivência dionisíaca, ao mesmo tempo que faz um elogio à estética do movimento, no qual as dimensões sensível e inteligível passam a vigorar com força e sem tirania de uma realidade determinando a outra. $\bigcirc$ sujeito se autopercebe como unidade indissociável. Quando apropriado na escola, permitindo ao aluno criar e recriar formas novas de jogar, o jogo se apresenta como espaço fecundo de liberdade criadora, situando os indivíduos como construtores e reconstrutores de sentidos de suas vidas, oportunizando-os à prática da autonomia e da ousadia.

Uma vez que o jogo passa a ser apropriado pela educação física como conteúdo de ensino, atividades como pique pega, queimado, amarelinha, futebol, voleibol e outros, não serão apenas meios para se atingir fins externos a essas atividades, mas antes, conhecimentos possuidores de valores em si mesmos que serão explorados, desenvolvidos e que fazem parte de uma determinada cultura, construídos ao longo das épocas, organizados e hierarquizados dentro de uma determinada sociedade, evocando traços míticos ancestrais reforçando e, ao mesmo tempo, ajudando a ressignificar sentidos de Ser e de agir dos indivíduos no mundo da vida, forjando novas sensibilidades através de novas representações. Vocês poderiam me perguntar, mas nesse caso o jogo não continua sendo um meio? Enquanto conhecimento universal e valor social, uma vez apropriado dentro do processo pedagógico, é claro que será um "meio" para educar os alunos, mas não um método na acepção utilitária do termo, um caminho que visa sempre a outra coisa que está além do próprio caminhar. Trata-se de uma outra natureza de ser "meio", pois, uma vez apropriado como conhecimento, ele será "meio" e fim em si mesmo: partiremos sempre do jogo e retornaremos sempre a ele como conteúdo capaz de ensinar, por meio de sua dinâmica, novas sensibilidades que podem ser objeto de reflexão e/ou de vivências cujo fim maior é apenas jogar pelo simples prazer de jogar. 
Nesse sentido, o objetivo deste artigo é refletir sobre o jogo como um dos conteúdos fundamentais de ensino da Educação Física, considerando-o a partir de seus pressupostos simbólico, mítico e estético.

\section{O CONTEÚDO SIMBÓLICO DO JOGO}

Segundo Gilbert Durand (1988) a consciência representa o mundo de duas maneiras: uma direta, na qual a coisa representada aparece pela sensação direta. Por exemplo, quando alguém fala em cachorro, há uma relação direta, uma imagem mental do animal cachorro, independente da raça, que torna possível não confundi-lo com um tigre; outra, indireta que se dá quando o objeto representado não traduz imediatamente todo o seu sentido, pois, não foi apreendido com total clareza pelas vias sensitivas e perceptivas. É o caso, por exemplo, das lembranças da infância, da imaginação que construía seres que povoavam a lua, marte etc. Nesse caso, o objeto ausente é de alguma forma reapresentado à consciência através de uma imagem que tende se aproximar o máximo possível do conjunto de sentidos que a representação indireta solicita.

A diferença entre o símbolo e o signo é que o signo estabelece uma relação direta com o significado, ou seja, significante (imagem mental) e significado (sentido) estão ligados por uma conexão causal, objetiva, e muito clara daquilo que visa a representar. Assim, ao sinal vermelho deve-se parar, ao sinal verde deve-se atravessar, ou ainda, diante de uma placa com dois ossos pintados em forma de " $x$ " cujo fundo é uma caveira humana, tem-se a idéia de perigo iminente.

Ou seja, a utilização do verde e do vermelho, dos ossos e da caveira são composições arbitrárias que indicam objetivamente aquilo que querem dizer e que permite a socialização desses pelos indivíduos em benefício da própria organização social. Mas, há casos em que o signo não é capaz de dar conta da realidade simplesmente através de suas relações arbitrárias construídas pela cultura. Quando, por exemplo, aquilo que vai ser representado por de uma imagem, busca sentidos de ordem espiritual ou moral, de difícil apreensão de forma objetiva, como a ideia de justiça, de liberdade, de paz, de amor.

O símbolo vai suscitar outro plano de consciência que não é o racional. Representa uma forma própria de significar alguma coisa ou alguém que não pode ser feito de uma outra maneira. $\bigcirc$ símbolo jamais poderá ser apreendido pelo pensamento ou pela representação direta, pois escapa à compreensão de tudo aquilo que ele quer significar. $\bigcirc$ símbolo, sempre deixa uma porta aberta pela qual, ao adentrá-la, o indivíduo depara-se com uma outra porta e assim infinitamente. Daí a relação entre significante e significado ser epifânica, isto é, acontecer num 
local onde seu profundo significado não pode ser apreendido pelo pensamento direto e que sempre aparece como constitutivo no interior do próprio processo de simbolização.

\section{UMA SINGELA ILUSTRAÇÃO: OS JOGOS COM BOLA, COM ARCOS, COM PNEUS...}

Além dos vários sentidos que motivam os alunos a participarem do jogo durante as aulas de Educação Física, os próprios objetos manipulados e a repetição de atitudes corporais no interior do jogo, encontram-se perpassadas de valores simbólicos que, em alguma medida, podem acionar no decorrer do próprio processo do jogado, sentidos que escapam à lógica imediata e previsível, podendo ser pedagogicamente orientadores de reflexões muito próprias.

Nos jogos com bola, com arcos, com pneus, a manipulação lúdica de objetos esféricos remete a uma interação do aluno com o significado simbólico do círculo e dos objetos circulares como um todo. E o circulo é um símbolo fundamental da perfeição, pois enreda, em si mesmo, a ideia de homogeneidade. O círculo é um ponto que se estende e retorna para seu início sem possuir divisões, etapas, e sem qualquer tipo de distinção em seu interior. Daí, muitas vezes, as figuras esféricas terem sido consideradas como o símbolo do mundo; os humanos ao se disporem em círculo estariam simbolicamente homenageando a própria existência enquanto seres integrados ao mundo, possibilitando a conexão com a energia cósmica criadora e consequentemente participarem da iluminação desta.

Nesse sentido, o círculo apresenta-se como uma totalidade indivisa, pois o seu movimento é perfeito, imutável, sem começo e nem fim, o que remete também a simbolização do próprio tempo, como a ideia de duração. Momentos representados pelo movimento cíclico do céu, da lua, do sol, da vida que nasce e morre diariamente. $\bigcirc$ círculo gira, a bola se movimenta, porque é o movimento que garante vida à forma circular. A figura redonda sendo a mesma do planeta representa também a perfeição, tal qual a cabeça arredondada dos humanos que fazem a bola movimentar-se e o jogo acontecer.

A ideia de que Deus está em toda parte, como centro do universo, é um tema que aparece em muitos autores da História das Religiões. E, ao que parece, esse caráter de acolhimento divino tende a remeter o círculo à simbologia da proteção, isto é, de uma proteção assegurada àqueles que participam de sua forma, dentro de seus limites. Pois, segundo Chevalier e Gheerbrant (1994, p. 254), "há lutadores que costumam traçar um círculo em volta de seu corpo, antes de travar o combate". Da mesma forma, círculos menores como argolas, anéis, colares, além de servirem como 
adornos de antigos guerreiros, também representavam profundamente a ligação entre o corpo e alma, oferecendo a proteção da unidade circular à unidade humana para permitir ao lutador mais segurança para desempenhar o combate.

Esse valor de proteção das formas circulares menores tende a explicar também o motivo pelo qual os mortos em muitas culturas, para poderem se elevar em direção à divindade, eram enterrados, queimados, embrulhados e embarcados em canoas sem qualquer espécie de adorno circular. Pois a alma tinha que assumir o seu desligamento com o corpo para poder se movimentar livre para a "além vida". Uma aliança, um anel de noivado ou casamento representa a ligação de duas pessoas que se amam, como braceletes e adornos de pescoço em muitas tribos representam a ligação do indivíduo com sua cultura ou divindade.

Isso implica em pensar que os jogos com objetos circulares ou realizados com a presença de arcos desenhados no chão, além de sua dimensão funcional, utilitária e profana, não deixa de ser também uma forma de reatualização de uma atividade que remonta a dimensões sagradas da nossa história ancestral. Ainda que saibamos que quando os alunos durante uma aula de Educação Física jogam um jogo com bola, alguns sentidos mais imediatos tendem a vigorar como, por exemplo, superar-se, superar o outro, jogar pelo simples prazer de jogar, dentre outros. Entretanto, a forma circular como a expressão simbólica do mundo evoca um fascínio e uma adesão emocional que não se explica somente como sendo fruto do nosso tempo contemporâneo, mas antes, como reavivamento de um tempo originário da humanidade.

Na medida em que o professor de Educação Física passa a valorizar a dimensão simbólica do jogo, ele será capaz de compreender melhor um sem número se representações do jogo, seja como ritual, como culto religioso, como luta entre a vida e a morte, como símbolo da vida, como manifestação do êxtase. Com isso, ele pode melhor compreender alguns sentidos profundos que motivam os alunos a jogarem e as questões que se apresentam no interior do jogo, a fim de aprofundar ou desconstruir determinados sentidos passíveis de serem apreendidos pelo esforço do pensamento racional.

\section{O CONTEÚDO MÍTICO DO JOGO: A DÍADE APOLO-DIONISO}

Segundo Brandão (1992), Apolo nasceu no dia sete do mês délfico Bísico que em nosso calendário situa-se entre a segunda metade de março e a primeira metade de abril. Conta-se que quando nasceu cisnes brancos deram sete voltas em torno da ilha de Delfos. Daí as festas principais em homenagem a Apolo acontecer no dia 7 de cada mês. 
Apolo é reconhecido como aquele que realiza a harmonia entre as partes, o equilíbrio entre as tensões. É o verdadeiro mediador das paixões humanas: longe de querer suprimi-las, Apolo tão somente trata de orientá-las no sentido de uma crescente espiritualização, ou consciência do homem de si mesmo.

A dimensão apolínea no jogo se manifesta quando da conduta do jogador pelo autocontrole em administrar a emoção de jogar, de driblar, de superar e de se autossuperar, considerando os limites e as possibilidades impostas pelas regras do jogo.

Após matar Píton, Apolo ficou um ano no Vale de Tempe a fim de purificar-se das manchas de sangue deixadas pelo dragão, as quais deveriam ser limpas para não contaminar o próprio deus. "Para perpetuar a memória do triunfo de Apolo sobre Píton e para se ter o dragão in bono animo (e este é o sentido dos Jogos Fúnebres), celebravam-se lá nas alturas do Párnaso, de quatro em quatro anos, os Jogos Píticos" (BRANDÃO, 1992, p. 93).

Um detalhe curioso diz respeito ao fato da premiação dos Jogos Olímpicos ser feita com uma coroa de louros. Em um dos amores mal sucedidos de Apolo, conta-se que o deus da beleza zomba do poder divino das flechas de Eros, filho de Afrodite. Eros, ao se ver humilhado, resolveu flechar Apolo com a seta do amor; e, por seu turno, flechou Dáfne com a flecha da aversão, da repulsa, da indiferença frente ao amor. Assim, apesar da beleza encantadora de Apolo, Dáfne fugiu para as montanhas e, ao se ver acossada pelo Apolo apaixonado, pediu a seu pai, Pereu, o deus-rio, que a transformasse em alguma coisa para se livrar do apaixonado. E foi transformada em uma árvore de louros (em grego dáphene), que se tornou a árvore predileta de Apolo e objeto simbólico das premiações dos jogos gregos.

Já Dioniso é o deus da metamorfose, da transformação, do permanente trânsito, do movimento encarnado que aproxima o homem dos imortais através do êxtase, da embriaguês, da brincadeira, da zombaria e do ato de se perder de si mesmo por meio da evasão da realidade decorrentes da profunda emoção vivida nos rituais dionisíacos.

Dioniso nasceu da coxa de Zeus, pois foi arrancado do ventre de sua mãe, Sêmele, por um raio enviado pelo próprio Zeus, que a fulminou, Dioniso tornou-se tão poderoso, em função da sua estreita proximidade com Zeus, que desceu até o fundo do Hades para de lá arrancar sua mãe e conferir-lhe imortalidade.

Dioniso, tão logo nasce, é levado para o monte Nise e entregue aos cuidados das Ninfas e Sátiros, que cuidavam dele numa sombria gruta com intensa vegetação e parreiras de uva maduras. Certa vez, já na sua adolescência, Dioniso colhe alguns desses cachos, espreme as frutas em sua taça de ouro e bebe o suco em companhia de seus protetores. Daí nasce o vinho, que, ao ser bebido repetidas vezes por Dioniso, pelas Ninfas e pelos Sátiros os coloca em estado de profunda 
embriaguês, levando-os a dançar vertiginosamente até caírem semidesfalecidos. A cada ano a propósito da colheita de uvas, festas com danças em homenagem a Baco ou Dioniso, em Atenas, passaram a acontecer festas onde se bebia até cair. Entretanto, este semidesfalecimento não era causado somente em função do efeito do vinho no organismo, mas também pelo êxtase e entusiasmo proporcionados por essas festas. "O sair de si implicava um mergulho de Dioniso em seu adorador através do (enthusiasmós), "entusiasmo". O homem, simples mortal, (antróphos), em êxtase e entusiasmo, comungando com a imortalidade, tornava-se (anér), isto é, herói, um varão que ultrapassa o (métron), a medida de cada um" (BRANDÃO, 1992, p. I32).

O sair de si implica numa integração maior com o deus Dioniso, e o entusiasmo é ter um deus dentro de si, isto é, identificar-se com ele, coparticipar da divindade. A possessão dionisíaca é a expressão máxima do homem com o divino através da celebração dos mistérios, a partir das orgias, do transe, do êxtase, da agitação incontrolável e frenética. Dito de outra maneira, a mania (a loucura sagrada) e a orgia fazem emergir com toda força a liberdade que se segue pela transformação, pela liberação de energias que, ao serem liberadas purificam-se.

Dioniso é o deus da metamorfose e do movimento que não conhece nem fronteiras nem culturas. Ao suscitar a embriaguês, o transe, o erotismo, a fertilidade, universaliza-se através de seus próprios temas, com isso passa a ser reconhecido como um deus universal. Surge com a mesma velocidade que desaparece: em lapsos, momentos mágicos e fugidios. A gratuidade plena durante o jogo, a alegria de jogar pelo simples prazer de jogar, a expansividade e a evasão da vida real durante o jogo é a presença marcante do espírito dionisíaco dentro do jogo.

Dioniso surge inesperadamente, brincando, saltando, dançando, passando rasteira, rasgando as coisas e punindo aqueles que o desrespeitam, levando-os ao delírio ensandecido, à loucura, à infâmia e até ao homicídio. A esse respeito, conta-se que o Rei Preto, da Argólia, tinha três filhas, todas elas se recusavam a prestar culto a Dioniso. De início, somente essas três foram punidas com a mania da loucura, mas logo em seguida todas as mulheres de Argólia foram atacadas pelo mesmo mal e passaram a matar seus próprios filhos, abandonaram suas casas e desapareceram nos bosques.

Da mesma forma que nas festas dionisíacas o vinho jorra da terra e das jarras dos apaixonados pela bebida, Dioniso apresenta-se saltitante e malicioso com as suas jogadas de pernas, por exemplo, através de inúmeras rasteiras dadas nos simples mortais, que fazem uns serem objeto de riso de outros; é o deus que traiçoeiramente leva as mulheres até o transe e aplica-lhes rasteiras impiedosamente.

Poderíamos, diante da nova observação feita acima, perguntar: se Dioniso aparece em suas festas com tanto sarcasmo, brincadeira, trapaça, punições, errâncias, metamorfoses, não teria ele muitos inimigos? A resposta é negativa. Isso porque 
Dioniso escolhe, seleciona o "palco" onde pode ser reconhecido como deus, ainda que nas suas várias formas e manifestações muito de humano ele apresente.

\section{O CONTEÚDO ESTÉTICO DO JOGO}

O poeta e dramaturgo alemão Friedrich Schiller (1990), diz que o verdadeiro homem no sentido profundo do termo, é aquele que joga. Schiller acredita que o homem, ao experimentar o estado lúdico, não está fugindo da realidade que o cerca, mas antes, concebendo uma nova vida aos que habitam sua sensibilidade na medida que momentaneamente se distancia destes para poder "vê-los" melhor. Assim, o impulso lúdico busca, sem qualquer finalidade externa à sua própria realização, potencializar a realidade humana, cujo fundamento maior é o lúdico, e, consequentemente, inscreve este mesmo homem numa nova possibilidade de se autoperceber e de perceber o próprio mundo que o circunscreve. Dito de outra maneira, ao mudar a percepção que o sujeito tem de si, a percepção que este tinha até então do mundo poderá também ser modificada por conta de uma nova sensibilidade.

A tensão permanente entre razão e emoção ou inteligível e sensível é o que define o homem como um ser diferente dos animais e consequentemente um ser que pode experimentar uma educação estética. Uma educação voltada para o movimento de jogo, o movimento próprio do sensível conduzindo-se ao inteligível e vice-versa é a maior expiração de uma educação profundamente humana.

O impulso lúdico é a expressão da tensão entre o impulso sensível, que tem como objeto a vida captada através dos sentidos imediatos, e o impulso inteligível, que tem como objeto as formas relacionadas ao pensamento, a razão. Dessa tensão trazida à tona pelo estado de jogo, o impulso lúdico cria o seu objeto que é a forma viva, isto é, a realização humana materializada numa forma que transcende a própria intencionalidade da realização; ela escapa ao homem, o transcende enquanto realidade capaz de ser apreendida por meio das palavras, se inscrevendo como a manifestação mais ampla do sentido de beleza.

Um bloco de mármore pode se tornar a forma-viva para o escultor. Imaginem a escultura "Le Baiser" de Rodin, "O Beijo", na qual há um homem e uma mulher se beijando sentados. A riqueza desta obra reside, dentre outras coisas, na sua própria ambiguidade de ser e ao mesmo tempo não parecer ser mármore. Ou seja, a expressividade do casal beijando-se nos remete a múltiplas interpretações, tais como, a figura da paixão, do carinho, do desejo ardente, da ternura etc., da mesma forma, que nos confunde pela sua "quentura", pelo fato de sua "vida" ter sido brotada de uma pedra tão fria, o mármore. E só tomamos sentido de que o casal é feito de mármore quando o tocamos, isto é, quando acionamos a dimensão 
sensível enquanto julgadora da realidade. Essa ambiguidade que se manifesta no jogo tenso entre o sensível (que reconhece a frieza da pedra mármore) e o inteligível (que remete ao beijo e aos sentidos socialmente construídos) é que torna impossível definir o que a escultura realmente é na sua totalidade, pois ao mesmo tempo em que ela é feita de um mineral duro, o movimento sugerido na ecultura é evidente. Da mesma forma que se o mármore é uma pedra fria, a cena do beijo e como ela se constrói é algo que remete a uma realidade quente, portadora de vida. Isto faz com que Rodin (o escultor) apareça na sua obra de arte confundido-se com o mármore e fazendo deste uma forma viva.

Significa dizer que quando apenas meditamos, pensamos sobre uma forma, sobre uma maneira de jogar um jogo, tais manifestações são inertes, meras abstrações; quando sentimos sua forma, quando damos início ao jogo, elas passam a se apresentarem como meras impressões. "Somente quando sua forma vive em nossa sensibilidade e sua vida se forma em nosso entendimento o homem é forma viva, e este será sempre o caso quando o julgamos belo" (SCHILLER, 1990, p. 82). Daí ser belo não a compreensão do jogo, ou mesmo quando começamos a jogar, mas quando após iniciado o jogo nos evadimos ludicamente nesse mundo, potencializando a nossa sensibilidade durante o ato de jogar.

O sentido profundo de jogo, nas reflexões de Schiller (|99|), é aquele em que seu maior fundamento é o impulso lúdico. Assim, podemos observar que para o jogo se tornar uma possibilidade de apreensão estética por parte do jogador ele tem de ser muito mais que um mero exercício, uma repetição, uma obrigação imposta por uma necessidade externa à sua própria realização. Mas antes, deve nascer de uma necessidade impulsionada pela liberdade de expressão daquele que joga.

No âmbito de uma Educação Física escolar, apreender o jogo como um conteúdo que pode suscitar uma experiência estética significa criar as condições do movimento do jogo com os alunos no sentido de fazer vigorar o entusiasmo, a alegria, a gratuidade e o compromisso dos alunos para com a beleza do próprio jogo como valor maior a ser perseguido.

Não basta ensinar aos alunos as regras do jogo ou os seus fundamentos principais para que a experiência estética vigore. Dominar as regras e os fundamentos do jogo significa apenas ter acesso à sua forma, fruto do impulso formal, racional, inteligível. Por outro lado, não basta a sensação imediata de alívio, de excitação e de prazer que irão remeter os alunos à experiência estética no sentido schilleriano, pois estaríamos diante do impulso sensível apenas. Para que a vivência estética do jogo aconteça e possa ser considerada uma ação bela, aquele que joga tem que estabelecer um sentido profundo com a ação que está realizando. Ao mesmo tempo em que joga, se coloca em jogo e é jogado pelo próprio movimento que deu início. Ou seja, um sentido 
que seja impulsionado pela liberdade de expressão e que no decorrer de sua ação, se construa e se reconstrua tantas vezes quantas forem necessárias.

O jogo, ao ser apropriado esteticamente, permite ao aluno, no plano do sensível, satisfazê-lo e remetê-lo a muitos outros sentimentos que ele é capaz de descrever, ainda que parcialmente. Ao mesmo tempo, no plano do inteligível ele se sinte transportado para um novo mundo onde sua ação não se limita a um mero cumprimento de regras e de gestos pré-determinados, mas os transcende na direção também do indizível, isto é, daquilo que se sente mas que não se consegue enunciar, fazendo com que o corpo vibre, se arrepie plenamente inscrevendo o conjunto de sensações por ele sentidas como plenas, absolutas, vividas com toda intensidade que Ihe cabe viver naquele momento mágico. Criando assim novas alternativas, improvisando as várias formas de se jogar pelo simples prazer de improvisar.

É nessa junção de forças, das múltiplas sensações vividas em estado de jogo e do conhecimento do jogo, que emerge a experiência estética, a forma viva experimentada pelo impulso lúdico, na qual o homem, como nos diz Schiller ( I99|), se torna realmente homem no sentido profundo do termo.

Para Schiller (199|), o homem não pode ser dominado por sua natureza ou pela sua razão, mas antes, estas duas dimensões, indissociáveis do homem, devem manifestar-se plena e independentemente e, ao mesmo tempo, perfeitamente unidas. Pois segundo Schiller, o homem opõe-se a si mesmo de duas maneiras, como selvagem, quando orienta sua vida baseada estritamente na sensibilidade, (se relaciona com a realidade através das impressões imediatas que seus sentidos captam) e como bárbaro, quando usa a razão para "domesticar"a todo preço a sensibilidade, pautando a vida num saber fazer, repetitivo, altamente previsível e mecânico em relação ao mundo.

Em estado estético o aluno é capaz de se perceber melhor, isto na medida em que ao se afastar momentaneamente da realidade ele é capaz de se autoperceber numa esfera diferenciada do real, onde as dimensões sensível e inteligível se apresentam enquanto objetos de contemplação, isto é, de reflexão para si próprio. É em outros termos, um autoconhecimento deflagrado pela evasão que o impulso lúdico sugere e que mostra com certa autonomia do mundo social o que realmente o indivíduo é ou gostaria de ser na esfera do jogo da vida.

\section{CONSIDERAÇÕES FINAIS}

Poderia, neste artigo, ter discutido o conteúdo jogo como um componente curricular da Educação Física, abordando o valor histórico inerente a cada jogo, suas 
transformações ao longo dos tempos, a relação dessas transformações com a tecnologia, com os interesses econômicos e políticos de uma época e sua apropriação atual considerando os aspectos ideológicos e alguns valores dominantes que evocam. Sem dúvida, uma apropriação do jogo como conteúdo de ensino não pode deixar de tematizar essas e outras questões dentro do escopo sócio-histórico-político. Entretanto, resolvi privilegiar uma abordagem que aos poucos vai se afirmando dentro do campo da Educação Física como relevante e imprescindível para a intervenção pedagógica do professor de Educação Física, a abordagem interdisciplinar dos estudos do imaginário social.

O imaginário não se opõe à realidade, muito pelo contrário, é o suporte mesmo desta. Antes de os sujeitos serem definidos como seres racionais, os humanos são seres que produzem desejos, sonhos, crenças, mitos, utopias e projetos que justificam o presente imediato. Não é à toa que muitas vezes nos sujeitamos ao desprazer, ao incômodo e à disciplina cansativa de determinadas atividades porque acreditamos, porque desejamos, porque sonhamos com a contemplação da beleza, com a alegria e com a felicidade desse investimento. O que significa dizer que o presente, ou melhor, as representações que os nossos alunos têm de si, do mundo que os cercam e das aulas de Educação Física se ancoram em fundamentos passados de uma história de vida particular e em projetos que ao mesmo tempo são singulares e reatualizações de sentimentos originários da humanidade, de maneira consciente e inconsciente, isto é, passível de ser dito, em certa medida, racionalmente e, ao mesmo tempo, fruto da intuição e da mobilização afetiva do aluno não redutível ao discurso racional, mas, manifestada por meio de pistas reveladoras através da linguagem corporal.

Nessa perspectiva, tratar do conteúdo jogo considerando as suas dimensões simbólica, mítica e estética, significa tratá-lo à luz do imaginário social, pois este é um amálgama, uma fusão dessas e de outras dimensões que não foram discutidas aqui, como, por exemplo, a dimensão ideológica, a dimensão da crença que se enreda na tensão entre o sagrado e o profano, a produção de desejos que se articula com a relação tensa entre prazer e desprazer, enfim, pensar o tema jogo nessa ótica não significa apenas realizar um exercício intelectual inócuo, fundamentado no puro deleite do pesquisador. Muito pelo contrário, trata-se de uma apropriação que leva em conta a produção subjetiva dos alunos articuladas com uma demanda afetiva e mágica inerente à própria condição humana. E, por questões óbvias, podemos dizer que quem possui maiores informações sobre o conteúdo que ensina e a partir daí começa a considerar também os diversos sentidos que os alunos podem atribuir às suas práticas através da elaboração de representações, terá mais subsídios e sensibilidade para intervir na formação integral do aluno, considerando-o não somente como aquele que possui necessidades físicas e racionais, mas também e fundamentalmente, como aquele que possui necessidades simbólicas, míticas e estéticas de se relacionar consigo e com o mundo. 
A mensagem fundamental é a de sinalizar para os professores de Educação Física, que atuam com o jogo como conteúdo de ensino, que a leitura e o aprofundamento das questões de ordem simbólica, mítica e estética do movimento não é uma questão menor ou acessória para a intervenção profissional. Muito pelo contrário, é o diferencial na intervenção profissional.

\section{The gamble as one of the fundamental contents in the social imaginary theory}

The main purpose of this article is to think about gamble as one of the fundamental contents of physical education teaching, in its symbolical, mythical and aesthetical aspects. This study is based in the social imaginary theory that comprehends the player action, despite its motivations, as a locus of senses that make the action of playing a significant and mysterious experience.

KEYWORDS: Gamble; imaginary; symbol; mythic; aesthetic.

\section{Le juego como contenudo de lo ensino em la perspectiva de los estudios de lo imaginário social}

La finalidad deste trabajo es reflejar sobre le juego como uno de los contenudos fundamental de lo ensino de la educacion física, lo respetando a partir de sus presupuesto simbólico, mítico y estético. La partir de lo recuerte interpretativo de los estúdios de lo imaginário social, comprendemos sin que para além de los inumerables significacións que motivam los jugadores a jugarem, existe tambiem, delante lo processo de lo acto de jugar, la emergência de algunos sentidos originários que reactalizam lo juego y lo jugar como una experiência significativa y, lo mismo tiempo, misteriosa.

PALAVRAS CLAVE: Juego; imaginário social; símbolo; mito; estética.

\section{REFERÊNCIAS}

BRANDÃO, J. de S. Mitologia Grega. Vol. II. Petrópolis: Vozes, 1992.

CHEVALIER, J. e GHEERBRANT, A. Dicionário de símbolos. Rio de Janeiro: José Olympio Editor, 1994.

DURAND, G. A imaginação simbólica. São Paulo: Cultrix, 1988.

O imaginário: ensaios acerca das ciências e da filosofia das imagens. Rio de Janeiro: Difel, 1994.

DUVINGNAUD, J. El juego del juego. México: Fundo de Cultura Econômica, 1997. 
DUFLO, C. O jogo: de Pascal a Schiller. Porto Alegre: Artued, 1999.

FINK, E. Le jeu comme symbole du monde. Paris: Les editions de minuit, 1993.

HUIZINGA, J. Homo ludens. São Paulo: Perspectiva, 1980.

LHÔTHE, J. M. Histoire dês jeux de société. Paris: Flammarion, 1994.

MAFFESOLI, M. Elogio da razão sensível. Petrópolis: Vozes, 1998.

RETONDAR, J. J. M. A produção imaginária dos jogadores compulsivos: a poética do espaço do jogo. São Paulo: Vetor, 2004.

Teoria do jogo - A dimensão lúdica da existência humana. Petrópolis: Vozes,

2007.

SCHILLER, F. A educação estética dos homens - numa série de cartas. São Paulo: lluminuras, 1990.

Poesia ingênua e sentimental. São Paulo: Iluminuras, 1991.

TUBINO, M. J. G. As teorias da educação física e do esporte: uma abordagem epistemológica. São Paulo: Manole, 2002.

VERNANT, Jean Pierre. O universo, os deuses, os homens. São Paulo: Companhia das Letras, 2000.

Recebido: 09 abr. 2009 Aprovado: 02 maio 201 I

Endereço para correspondência: Jeferson José Moebus Retondar Rua Marechal Maurício José Cardoso, 35/304 Bairro Correas Petrópolis - RJ CEP: 25730-013 